\title{
PERAN BRAND IMAGE MEMEDIASI PENGARUH E-WOM TERHADAP NIAT KONSUMEN MENGGUNAKAN OVO MOBILE PAYMENT
}

\author{
Ni Wayan Krisnawati ${ }^{1}$ \\ I Gde Ketut Warmika ${ }^{2}$
}

\author{
Fakultas Ekonomi dan Bisnis Universitas Udayana, Bali, Indonesia. \\ email : krisnaanik67@gmail.com
}

\begin{abstract}
ABSTRAK
Niat beli adalah tahap di mana konsumen membuat keputusan antara beberapa merek, dan akhirnya memilih alternatif yang paling mereka sukai atau proses yang dialami oleh konsumen dalam memutuskan barang mana atau layanan untuk membeli berdasarkan berbagai pertimbangan. Penelitian ini dilakukan dengan dasar untuk mengatahui hubungan antara E-WOM pada purchase intentiondengan dimediasi variabel brand image. Penelitian ini dilakukan pada calon pengguna OVO mobile payment, dengan sampel penelitian sebanyak 110 orang di Kota Denpasar, menggunakan metode nonprobability sampling yaitu purposive sampling.. Pengumpulan data menggunakan kuesioner yang disebarkan melalui online dan offline. Teknis analisis yang digunakan adalah teknik analisis deskriptif dan teknik analisis inferensial. Hasil yang didapatkan yaitu ditemukan adanya pengaruh positif antara E-WOM pada brand image, ditemukan adanya pengaruh positif antara EWOM padapurchase intention, ditemukan adanya pengaruh positif antara hubungan brand imageterhadap purchase intention, danbrand image memediasi pengaruh E-WOM terhadap purchase intention.
\end{abstract}

Kata kunci: brand image, E-WOM, purchase intention.

\begin{abstract}
Purchase intention is the stage where consumers make decisions between several brands, and finally choose the alternative they like best or the process experienced by consumers in deciding which goods or services to buy based on various considerations. This research was conducted on the basis of knowing the relationship between E-WOM on purchase intention and mediated by brand image variables. This research was conducted on prospective OVO mobile payment users, with a study sample of 110 people in Denpasar City, using a nonprobability sampling method namely purposive sampling. Data collection using questionnaires distributed through online and offline. The technical analysis used is descriptive analysis techniques and inferential analysis techniques. The results obtained are found that there is a positive influence between E-WOM on brand image, found a positive influence between E-WOM on purchase intention, found a positive influence between brand image purchase intention relationships, and brand image mediates the influence of E-WOM on purchase intention .
\end{abstract}

Keywords: brand image, E-WOM, purchase intention. 


\section{PENDAHULUAN}

Globalisasi dan perkembangan teknologi mampu mengubah gaya hidup orang-orang di seluruh dunia. Internet telah menjadi bagian penting dari kehidupan yang mengubah cara berkomunikasi. Dengan perkembangan industri telekomunikasi nirkabel di Indonesia, industri perbankan di Indonesia mengalami perkembangan yang signifikan dengan produk-produk perbankan yang beragam. Mobile payment menjadi salah satu inovasi pada metode pembayaran yang mulai banyak digunakan jaman sekarang. Segala kemudahan yang ditawarkan oleh mobile payment membuat semakin banyak masyarakat memilih untuk menggunakan mobile payment.

OVO merupakan mobile payment yang launching pada tahun 2017 milik perusahaan Lippo Group.Aplikasi OVO mengakomodasi berbagai kebutuhan terkait dengan cashless dan mobile payment.OVO dapat diunduh melalui platform Android dan iOS. Adanya merchant ataupun retail yang bekerja sama dengan OVO, merupakan sebuah value preposition OVO dalam menjalankan bisnis payment digital. OVO juga selalu memberikan tawaran-tawaran menarik berupa diskon maupun cashback apabila melakukan transaksi pada retail offline menggunakan pembayaran melalui aplikasi OVO. Menggunakan OVO, konsumen tidak perlu membawa uang tunai untuk berbelanja ataupun makan di beberapa restoran yang sudah terintegrasi dengan layanan OVO. OVO juga mengurangi terjadinya pencurian atau kehilangan uang yang terjadi dilingkungan. OVO mampu memantapkan diri sebagai aplikasi finansial dengan menambah fitur-fitur yang ada pada aplikasinya dan memberikan program-porgram baru yang mampu menarik perhatian sehingga menimbulkan niat masyarakat untuk menggunakan OVO.

Niat membeli adalah tahap di mana konsumen membuat keputusan antara beberapa merek, dan akhirnya membeli alternatif yang paling mereka sukai atau proses yang dialami oleh konsumen dalam memutuskan barang mana atau layanan untuk membeli berdasarkan berbagai pertimbangan (Annafik \& Rahardjo, 2012). Konsumen melakukan evaluasi terhadap manfaat dan nilai yang dirasakan dan kemudian memunculkan niat beli (Wang \& Tsai, 2014).

Electronic word of mouth menjadi salah satu variabel yang dapat mempengaruhi niat beli konsumen. E-WOM menjadi salah satu pertimbangan konsumen dikarenakan E-WOM adalah informasi yang didapatkan konsumen secara online dimana informasi ini mudah untuk diakses dan banyak konsumen mengandalkan E-WOM. Konsumen memiliki anggapan bahwa E-WOM penting dijadikan pertimbangan dalam pengambilan keputusan karena informasi didalam E-WOM tersebut selain mudah diakses, berisikan pengalaman-pengalaman konsumen lainnya yang kemudian dapat dijadikan referensi dalam pengambilan keputusan Hsu et al. (2013). 15 orang responden dari 20 responden yang diwawancara secara terbuka menyatakan bahwa awal mula mereka mengetahui mengenai OVO adalah dari media sosial.

Kotler dan Amstrong (2012) menyatakan bahwa sekumpulan keyakinan terhadap suatu merek disebut citra merek.Komunikasi dari mulut ke mulut yang positif bisa sangat bermanfaat mempengaruhi citra merek.Citra yang dibuat melalui komunikasi ini mungkin memiliki dampak besar pada produk atau 
layanan dan dampak ini mungkin dalam bentuk permintaan yang lebih besar oleh yang baru konsumen untuk produk atau layanan (Febriana \& Rumyeni., 2016). Menurut Prabandari et al. (2018) menunjukan hasil brand image memediasi pengaruh positifantara WOMterhadap purchase intention. Hal ini dapat dijelaskan bahwa konsumen yang memberikan rekomendasi terhadap suatu produk akan memperkuat citra merek produk tersebut dan citra merek ini yang memperkuat rekomendasi konsumen agar intensi pembelian meningkat.

Respon atau tindakan yang dilakukan oleh konsumen ketika akan membeli tapi belum melakukan pembelian disebut dengan niat beli (Martinez \& Soyoung, 2012).Para pengusaha menjadikan niat beli sebagai alat ukur untuk kemungkinan sikap konsumen di masa yang akan datang.Niat konsumen dalam mengeksplor informasi mengenai suatu produk menjadi salah satu indikator yang dapat digunakan untuk mengukur niat beli (Ferdinand, 2002). Selain itu, adanya ketertarikan konsumen dalam menggunakan atau ingin memiliki suatu produk juga dapat dijadikan indikator pengukuran niat beli (Calvin \& Samuel, 2014).

Penyampaian informasi mengenai bisnis kepada sanak saudara, keluarga, atau orang-orang sekitar serta orang asing merupakan pengertian dari Word Of Mouthmenurut (Al-Zu'bi, 2011). WOM tidak hanya dilakukan oleh pemilik dari produk yang dipasarkan tetapi juga dilakukan oleh konsumen yang telah memiliki kepercayaan terhadap produk tersebut atau konsumen yang memiliki pengalaman terkait dengan produk tersebut (Al-Zu'bi, 2011). Konsumen yang memiliki tingkat kepercayaan tinggi terhadap suatu produk, cenderung akan melakukan pembelaan dan memberikan informasi positif mengenai produk tersebut. Informasi yang dihasilkan dari WOM merupakan informasi berdasarkan pengalaman(Mowen \& Minor, 2002). Penyebaran komunikasi selain melalui penyebaran isu yang berasal dari mulut ke mulut (word of mouth) juga dapat melalui electronic word of mouth (E-WOM).

Media online telah melahirkan kata elektronik dari mulut ke mulut yang memiliki lebih interaktif kemampuan dan meningkatkan interaksi konsumen satu sama lain di dunia digitalmisalnya Wikipedia, Facebook dan Twitter, dll. Saat ini, sebagian besar konsumen mengandalkan informasi online yang dibuat atau dibagikan oleh orang lain untuk membuat keputusan yang dibeli (Hsu et al., 2013). Di era sekarang, semua orang menggunakan internet dalam kehidupan sehari-hari, dengan demikian, konsumen berkontribusi dan terlibat dalam kata elektronik dari mulut ke mulut sebelum dan sesudah pembelian produk apa pun (Berger \& Luckmann, 1966).

Ketika konsumen memberikan informasi yang positif melalui WOM, dampak yang dihasilkan dari hal tersebut adalah dampak positif pada produk yang disebutkan oleh konsumen. Komentar positif ini membantu perusahaan dalam membentuk citra yang baik dimata masyarakat. Namun WOM tidak hanya memberikan informasi positif. Informasi negatif sangat mungkin disampaikan oleh konsumen jika memang konsumen memiliki pengalaman negatif yang dirasakan atau nilai yang dianggap oleh konsumen tidak sesuai.

Jalilvand \& Samiei (2012) penelitian-penelitian sebelumnya yang mengangkat topik mengenai hubungan E-WOM pada brand image mendapatkan hasil bahwa E-WOM memiliki pengaruh pada brand image. Penelitian yang 
dilakukan oleh Sarah \& Rubiyanti (2016) menemukan adanya pengaruh positif antara hubungan E-WOM pada citra merek. E-WOM memberikan informasi kepada calon customer mengenai produk yang akan dibelinya. Informasi yang diberikan oleh E-WOM cenderung informasi dari konsumen yang telah menggunakan produk tersebut dan menceritakan pengalamannya dalam menggunakan produk tersebut. Jika feedback yang diberikan positif hal tersebut akan berdampak pada positifnya citra merek dari produk tersebut begitu juga sebaliknya.

Putri \& Prabowo (2015) serta Sa'ait et al. (2016) juga menemukan hasil yang serupa mengenai hubungan antara E-WOM terhadap brand image. Cong \& Zheng (2017), dan Saleem et al. 2013), Elseidi \& El-Baz (2016), Anggitasari (2016), Samuel \& Lianto (2014), Adriyati \& Indriani (2017) menemukan hasil bahwa E-WOM berpengaruh signifikan positif terhadap minat beli. Penelitian Faresha \& Hendrawan (2017) menyatakan bahwa E-WOM berpengaruh secara positif terhadap citra merek dan Prabandari et al. (2018) menyatakan bahwa WOM positif berpengaruh secara positif dan signifikan terhadap citra merek Teh Pucuk Harum di Kota Denpasar.

$\mathrm{H}_{1}$ : E-WOM memiliki pengaruh positif dan signifikan terhadap brand image

Informasi yang terdapat pada E-WOM baik informasi dengan sinyal positif maupun informasi dengan sinyal negatif dapat mempengaruhi niat beli dari konsumen. Ketika suatu produk mendapat ulasan yang buruk, hal tersebut akan berdampak pada niat beli masyarakat kepada produk tersebut. Persepsi masyarakat mengenai produk dengan ulasan buruk tentu akan mempengaruhi pertimbangan konsumen ketika akan membeli suatu produk. Penelitian yang dilakukan oleh Sarah \& Rubiyanti (2016), Putri \& Prabowo (2015), Sa'ait et al. (2016) menemukan adanya hubungan positif antara E-WOM pada niat beli.

Cong \& Zheng (2017), dan Saleem et al. (2013), Elseidi \& El-Baz (2016), Anggitasari (2016), Samuel \& Lianto (2014), Adriyati \& Indriani (2017) menemukan hasil bahwa E-WOM berpengaruh positif signifikan terhadap minat beli.Penelitian oleh Akbar \& Rosita (2017) menemukan bahwa E-WOM memiliki pengaruh pada niat pembelian aplikasi music streaming JOOX. Hasil penelitian oleh Prabandari et al. (2018) menunjukkan bahwa E-WOM menunjukkan hasil yang positif dan signifikan terhadap niat beli Teh Pucuk Harum.

$\mathrm{H}_{2}$ :E-WOM memiliki pengaruh positif dan signifikan terhadap

purchase intention

Penelitian oleh Wang \& Yang (2010) menemukan bahwa kredibilitas merek memiliki pengaruh terhadap niat beli konsumen pada industri otomotif di China.Penelitian oleh Rahmawan \& Pramono (2016) menemukan bahwa citra merek berpengaruh positif terhadap niat beli konsumen produkHandphone Xiaomi di Malang.Aberdeen (2016), Maghfiroh et al. (2016), Pradipta \& Mashariono(2015) dalam penelitian yang dilakukannya menemukan adanya hubungan positif antara citra merek pada niat beli pelanggan.

Terdapat beberapa penelitian sebelumnya yang memiliki hasil yang serupa mengenai hubungan antara citra merek pada niat beli yaitu penelitian yang dilakukan oleh Randi \& Heryanto (2016), Wang \& Tsai (2014). Pentingnya citra dari suatu merek harus diperhatikan oleh perusahaan karena akan memiliki 
dampak pada niat beli dari konsumen. Hal ini dikarenakan orang cenderung menghindari produk dengan citra yang buruk dan lebih memilih produk yang memiliki citra yang baik. Temuan hasil yang serupa ditemukan oleh Suwarduki et al. (2016), Kamilah \& Aniek (2017), Lien et al. (2015),Anggitasari (2016)dalam penelitiannya menemukan adanya hubungan yang positif antara hubungan brand image pada purchase intention.

$\mathrm{H}_{3}:$ Brand image memiliki pengaruh positif dan signifikan terhadap

purchase intention

Penelitian yang dilakukan oleh Torlak et al. (2014),Faharani et al. (2011), Jalilvand \& Samiei (2012), Anggitasari (2016), Samuel \& Lianto (2014), Elseidi \& El-Baz(2016), Adriyati \& Indriani (2017) menyatakan bahwa bahwa E-WOM berpengaruh positif terhadap minat beli dengan citra merek sebagai variabel mediasi.Hasil yang tidak jauh berbeda ditemukan pada penelitian yang dilakukan oleh Agus \& Iswara (2017), dalam penelitian tersebut diketahui citra merek merupakan variabel pemediasi yang turut mempengaruhi dan menentukan efektifitas pengaruh E-WOM terhadap niat beli.Hasil penelitian oleh Prabandari et al.(2018) menunjukkan bahwa brand imagemenunjukkan hasil yang positif dan signifikan dalam memediasi WOM positif terhadap niat beli Teh Pucuk Harum.

$\mathrm{H}_{4}$ :Brand image mampu memediasi E-WOM terhadap purchase intention

\section{METODE PENELITIAN}

Penelitian ini dilakukan pada calon pengguna aplikasi OVO di Kota Denpasar. Alasan memilih lokasi ini, karena melihat dari beberapa pertimbangan yakni, Denpasar merupakan Ibu Kota provinsi, Denpasar yang kini sebagai pusat kota dengan jumlah penduduk yang padat sehingga memerlukan alat pembayaran yang mudah dan cepat, masyarakat di Kota Denpasar cepat menyerap trend-trend yang berkembang, dengan adanya pengaruh dari kecepatan akses teknologi membuat Kota Denpasar menjadi sasaran untuk produk-produk unik dan inovatif, niat beli menjadi objek dari penelitian.

Data primer yang digunakan pada penelitian berasal dari hasil penyebaran kuesioner pada responden. Populasi penelitian yaituseluruh warga Kota Denpasar yang berniat untuk menggunakan aplikasi OVO mobile payment yang jumlahnya tidak dapat diketahui dengan pasti.

Teknik penentuan sampel dalam penelitian ini menggunakan teknik nonprobability sampling. Teknik nonprobability sampling yang dipilih adalah purposive sampling. Kriteria penentuan sampel adalah sebagai berikut responden berusia minimal 17 tahun, jenjang pendidikan minimal SMA, responden belum pernah menggunakan OVO mobile paymet, responden yang berniat untuk menggunakanOVO mobile paymet, dan berdomisili di Kota Denpasar.

Penulis memilih untuk menggunakan saran untuk melakukan analisis multivariate, jumlah indikator yang akan digunakan dalam penelitian ini adalah sebagai berikut : 11 indikator $\times 10=110$ responden. Metode pengumpulan data dalam penelitian ini menggunakan instrument wawancara dengan menyebar kuesioner. Skala likert menjadi alat ukur pada pertanyaan-pertanyaan dalam kuesioner. 
Tabel 1.

\section{Pengukuran Variabel Penelitian}

\begin{tabular}{lllll}
\hline No. & Variabel & \multicolumn{2}{l}{ Indikator } & Sumber \\
\hline 1 & E-WOM (X) & 1) & Memperoleh informasi & \\
& & 2) & Memperoleh rekomendasi & Prakoso al, (2016) \& Aditya \\
& & 3) & Memperoleh ajakan untuk & dan Wardana (2017) \\
& & memiliki & \\
2 & Brand Image (M) & 1) & Citra positif & Arsita \& Astuti (2011) \\
& & 2) & Ciri khas yang berbeda & \& \\
& 3) & Dikenal masyarakat luas & Shimp (2014: 40) \\
& 4) & Favorable & \\
3 & Purchase Intention & 1) & Nilai eksploratif & \\
& (Y) & 2) & Ketertarikan terhadap produk & Ferdinand (2002: 129) \\
& 3) & Ketertarikan untuk mencoba & \& \\
& & produk & Calvin \&Hatane (2014) \\
& 4) & Berniat untuk menggunakan \\
& & produk & \\
\hline
\end{tabular}

Sumber :Penelitian Sebelumnya

Tabel 2.

Alternatif Jawaban Responden

\begin{tabular}{lll}
\hline Alternatif Jawaban Responden & Kode & Skor \\
\hline Sangat Setuju & SS & 5 \\
Setuju & S & 4 \\
Cukup Setuju & CS & 3 \\
Tidak Setuju & TS & 2 \\
Sangat Tidak Setuju & STS & 1 \\
\hline Sumber: Sugiyono, 2015 & &
\end{tabular}

\section{HASIL DAN PEMBAHASAN}

Responden dalam penelitian ini berjumlah 110 orang, sesuai dengan ukuran sampel yang digunakan. Responden penelitian digambarkan secara umum dengan menyajikan karakteristiknya dilihat dari umur, jenis kelamin, pekerjaan dan penghasilan yang disajikan pada Tabel 3.

Umur kisaran 17 sampai 22 tahun mendominasi dalam penelitian ini dengan persentase sebesar 77,27 persen, yang menandakan bahwa pada rentang umur inilah responden lebih memilih mobile payment untuk pembayaran. Kemudian diikuti oleh rentan umur 23 sampai 28 tahun, menempati posisi kedua yaitu dengan persentase mencapai 15,45 persen, rentan umur 29 sampai 32 tahun memiliki persentase yang sama dengan rentan umur 33 sampai 38 tahun yaitu sebesar 1,82 persen. Terakhir yaitu umur yang lebih dari 38 tahun memiliki persentase sebesar 3,64.

Pada penelitian ini, responden perempuan memiliki presentase lebih banyak dibandingkan responden laki-laki. Persentase untuk responden perempuan yaitu sebesar 59,10 persen, sedangkan untuk responden laki-laki yaitu sebesar 40,90 persen. Responden dengan status sebagai pelajar/mahasiswa mendominasi yaitu dengan presentase sebanyak 59,10 persen, kemudian disusul oleh responden dengan pekerjaan sebagai pegawai swasta/ kontrak dengan presentase sebanyak 27,27 persen. Pada posisi ketiga ditempati oleh responden dengan pekerjaan wiraswasta yaitu sebesar 10 persen. Responden dengan pekerjaan sebagai PNS 
(pegawai negeri sipil) dan IRT (Ibu Rumah Tangga) masing-masing memiliki presentase sebesar 2,73 persen dan 0,9 persen.Responden dengan pendapatan kurang dari Rp. 500.000 mendominasi dengan presentase sebesar 36,36 persen, kemudian disusul dengan pendapatan yang lebih dari Rp. 2.000.000 dengan presentase 24,55 persen. Di posisi ketiga ditempati oleh responden yang memiliki pendapatan sekitar Rp.1.500.000 sampai Rp.2.000.000 dengan presentase sebesar 14,55 persen, presentase 13,64 persen ditempati oleh responden yang memiliki pendapatan sebesar Rp.1.000.000 sampai dengan Rp. 1.500.000 diposisi terakhir ditempati oleh responden dengan pendapatan Rp.500.000 sampai dengan Rp. 1.000 .000 dengan presentase sebesar 10,90 persen.

Tabel 3.

Karakteristik Responden

\begin{tabular}{|c|c|c|c|c|}
\hline No. & Variabel & Klasifikasi & $\begin{array}{l}\text { Jumlah } \\
\text { (orang) }\end{array}$ & $\begin{array}{c}\text { Persentase } \\
(\%)\end{array}$ \\
\hline \multirow{6}{*}{1.} & & $17-22$ tahun & 85 & 77,27 \\
\hline & & $23-28$ tahun & 17 & 15,45 \\
\hline & Umur & 29-32 tahun & 2 & 1,82 \\
\hline & & $33-38$ tahun & 2 & 1,82 \\
\hline & & $>38$ tahun & 4 & 3,64 \\
\hline & Jumlah & & 110 & 100 \\
\hline \multirow[t]{5}{*}{2 . } & Jenis Kelamin & Laki-laki & 45 & 40,90 \\
\hline & & Perempuan & 65 & 59,10 \\
\hline & Jumlah & & 110 & 100 \\
\hline & & Pelajar/Mahasiswa & 65 & 59,10 \\
\hline & & PNS & 3 & 2,73 \\
\hline \multirow[t]{6}{*}{3.} & Pekerjaan & Pegawai Swasta/Pegawai Kontrak & 30 & 27,27 \\
\hline & & Wiraswasta & 11 & 10 \\
\hline & & Ibu Rumah Tangga & 1 & 0,9 \\
\hline & Jumlah & & 110 & 100 \\
\hline & & $<$ Rp. 500.000 & 40 & 36,36 \\
\hline & & Rp.500.000<Rp.1.000.000 & 12 & 10,90 \\
\hline \multirow[t]{4}{*}{4.} & $\begin{array}{l}\text { Penghasilan/ } \\
\text { Uang Saku }\end{array}$ & Rp.1.000.000<Rp.1.500.000 & 15 & 13,64 \\
\hline & & Rp.1.500.000 <Rp.2.000.000 & 16 & 14,55 \\
\hline & & $>$ Rp.2.000.000 & 27 & 24,55 \\
\hline & Jumlah & & 110 & 100 \\
\hline
\end{tabular}

Sumber:Data diolah, 2019

Uji Validitas digunakan agar instrument penelitian dapat dinyatakan valid dan dapat digunakan maka syarat yang harus dipenuhi adalah skor total pertanyaan harus melebihi 0,03 . Instrument penelitian yang digunakan berhasi melebihi 0,03 sehingga semua butir pernyataan valid dan dapat digunakan. 
Tabel 4.

Hasil Uji Validitas

\begin{tabular}{|c|c|c|c|c|}
\hline No & Variabel & Item Pernyataan & $\begin{array}{c}\text { Korelasi } \\
\text { Item Total }\end{array}$ & Keterangan \\
\hline \multirow{4}{*}{1} & \multirow{3}{*}{ E-WOM (X) } & Memperoleh informasi & 0.861 & Valid \\
\hline & & Memperoleh rekomendasi & 0.957 & Valid \\
\hline & & Memperoleh ajakan untuk mencoba & 0.931 & Valid \\
\hline & \multirow{4}{*}{$\begin{array}{l}\text { Brand Image } \\
\text { (M) }\end{array}$} & Citra positif & 0.821 & Valid \\
\hline \multirow{3}{*}{2} & & Ciri khas yang berbeda & 0.732 & Valid \\
\hline & & Dikenal masyarakat luas & 0.724 & Valid \\
\hline & & Favorable & 0.845 & Valid \\
\hline \multirow{4}{*}{3} & \multirow{4}{*}{$\begin{array}{c}\text { Purchase } \\
\text { Intention }(\mathrm{Y})\end{array}$} & Nilai eksploratif & 0.831 & Valid \\
\hline & & Ketertarikan terhadap produk & 0.881 & Valid \\
\hline & & Ketertarikan untuk mencoba produk & 0.923 & Valid \\
\hline & & Berniat untuk menggunakan produk & 0.900 & Valid \\
\hline
\end{tabular}

Tabel 5.

Hasil Uji Reliabilitas

\begin{tabular}{clcc}
\hline No. & \multicolumn{1}{c}{ Variabel } & Cronbach's Alpha & Keterangan \\
\hline 1 & E-WOM $(\mathrm{X})$ & 0.904 & Reliabel \\
2 & Brand Image $(\mathrm{M})$ & 0.788 & Reliabel \\
3 & Purchase Intention $(\mathrm{Y})$ & 0.904 & Reliabel \\
\hline
\end{tabular}

Sumber : Data diolah, 2019

Setelah dilakukan uji reliabilitas pada instrument yang digunakan, hasil yang didapatkan adalah instrument penelitian reliabel dan dapat diandalkan. Hasil ini berdasarkan seluruh nilai Alpha Cronbach yang melebihi 0,60 dimana 0,06 merupakan batas yang telah ditentukan. Syarat agar instumen dikategorikan sebagai instrument yang reliabel adalah dengan nilai cronbach's alpha yang melebihi 0,06 .

Tabel 6.

Deskripsi Penilaian Responden terhadap variabel Purchase Intention

\begin{tabular}{|c|c|c|c|c|c|c|c|c|}
\hline \multirow[b]{2}{*}{ No } & \multirow[b]{2}{*}{ Pernyataan } & \multirow{2}{*}{\multicolumn{5}{|c|}{$\begin{array}{c}\text { Frekuensi Jawaban } \\
\text { Resnonden }\end{array}$}} & \multirow{2}{*}{$\begin{array}{l}\text { Rata- } \\
\text { rata }\end{array}$} & \multirow[t]{2}{*}{ Keterangan } \\
\hline & & STS & & $\begin{array}{l}\text { ondel } \\
\text { CS }\end{array}$ & $\mathbf{S}$ & SS & & \\
\hline 1 & $\begin{array}{l}\text { Saya berniat untuk mencari } \\
\text { informasi mengenai OVO. }\end{array}$ & 5 & 16 & 36 & 38 & 15 & 3.38 & Sedang \\
\hline 2 & $\begin{array}{l}\text { Saya tertarik dengan OVO } \\
\text { setelah mendapatkan } \\
\text { informasi mengenai produk } \\
\text { ini }\end{array}$ & 4 & 10 & 37 & 46 & 13 & 3.49 & Tinggi \\
\hline 3 & $\begin{array}{l}\text { Saya tertarik untuk mencoba } \\
\text { OVO }\end{array}$ & 2 & 13 & 36 & 45 & 14 & 3.51 & Tinggi \\
\hline 4 & $\begin{array}{l}\text { Saya berniat } \\
\text { menggunakan OVO. }\end{array}$ & 5 & 9 & 32 & 45 & 19 & 3.60 & Tinggi \\
\hline & Rata-rata variabe & urcha & Inter & & & & 3.49 & Tinggi \\
\hline
\end{tabular}

Sumber : Data diolah, 2019 
Rata-rata yang dihasilkan dari seluruh persepsi responden terhadap purchase intention pada penelitian ini yaitu 3,49. Nilai ini termasuk pada kategori tinggi. Secara keseluruhan responden merepresentasikan bahwa sebagian besar responden memiliki niat untuk mencoba produk OVO. Serta responden tertarik untuk mencari informasi tentang produk OVO. Berdasarkan hasil deskripsi persepsi konsumen mengenai niat beli konsumen yang diukur dengan 4 indikator, cenderung menunjukkan nilai rata-rata tertinggi pada pernyataan "Saya berniat untuk menggunakan OVO" dengan nilai sebesar 3,60. Hal ini menunjukkan bahwa secara keseluruhan responden berniat untuk mencoba produk OVO. Sedangkan nilai yang terendah yaitu 3,38 pada indikator mencari informasi ", Saya berniat untuk mencari informasi mengenai OVO".

3 pernyataan digunakan untuk mengukur variabel eksogen dari penelitian ini yaitu variaberl e-WOM. Hasil yang didapatkan dari penyebaran kuesioner kepada responden mengenai persepsi responden terhadap E-WOM pada OVO mobile paymentdisajikan pada tabel berikut.

Tabel 7.

Deskripsi Penilaian Responden terhadap variabel E-WOM

\begin{tabular}{|c|c|c|c|c|c|c|c|c|}
\hline \multirow[t]{2}{*}{ No } & \multirow[t]{2}{*}{ Pernyataan } & \multicolumn{5}{|c|}{$\begin{array}{c}\text { Frekuensi Jawaban } \\
\text { Responden }\end{array}$} & \multirow[t]{2}{*}{$\begin{array}{l}\text { Rata- } \\
\text { rata }\end{array}$} & \multirow[t]{2}{*}{ Keterangan } \\
\hline & & STS & TS & CS & $\mathbf{S}$ & SS & & \\
\hline 1 & $\begin{array}{l}\text { Saya memperoleh informasi } \\
\text { mengenai OVO }\end{array}$ & 6 & 13 & 45 & 28 & 18 & 3.35 & Sedang \\
\hline 2 & $\begin{array}{l}\text { Saya mendapatkan } \\
\text { rekomendasi untuk mencoba } \\
\text { OVO }\end{array}$ & 7 & 18 & 31 & 38 & 16 & 3.35 & Sedang \\
\hline 3 & $\begin{array}{l}\text { Saya memperoleh ajakan } \\
\text { untuk mencoba OVO }\end{array}$ & 6 & 18 & 28 & 37 & 21 & 3.45 & Tinggi \\
\hline \multicolumn{7}{|c|}{ Rata-rata variabel E-WOM } & 3,38 & Sedang \\
\hline
\end{tabular}

Hasil perhitungan pada Tabel 7. menunjukkan bahwa nilai responden yang paling tertinggi yaitu 3,45 pada indikator memperoleh ajakan untuk mencoba OVO dengan pernyataan " Saya memperoleh ajakan untuk mencoba OVO". Sedangkan nilai yang terendah yaitu 3,35 pada indikator informasi dan rekomendasi produk OVO, dengan pernyataan " Saya memperoleh informasi mengenai OVO" dan pernyataan "Saya mendapatkan rekomendasi untuk mencoba OVO". Rata-rata yang dihasilkan dari seluruh persepsi konsumen terhadap variabel E-WOM adalah 3,38. Nilai ini terkmasuk kategori sedang. Hal ini berarti secara keseluruhan responden merepresentasikan bahwa informasi, dan rekomendasi untuk mencoba OVO pada tingkat sedang dan sebagian besar responden pada penelitian ini memperoleh ajakan untuk mencoba produk OVO.

Variabel brand image dalam penelitian ini merupakan variabel mediasi yang diukur menggunakan 4 pernyataan. Hasil penelitian mengenai persepsi responden terhadap brand image tersaji pada Tabel 8 . Hasil perhitungan pada Tabel 8 menunjukkan bahwa nilai responden yang paling tertinggi yaitu 3,50 merupakan indikator image positif dan merek yang mudah diingat oleh konsumen, dengan pernyataan "OVO memilki image positif dalam benak saya" 
dan pernyataan" OVO adalah merek yang mudah diingat di benak saya". Sedangkan nilai yang terendah yaitu 3,36 pada indikator OVO dikenal luas oleh masyarakat, dengan pernyataan "OVO dikenal luas oleh masyarakat khususnya di Kota Denpasar".

Rata-rata keseluruhan persepsi responden mengenai variabel brand image adalah sebesar 3,46. Nilai rata-rata yang dihasilkan termasuk pada kategori baik. Hal ini berarti secara keseluruhan responden merepresentasikan bahwa tingkat brand image atau citra merek OVO baik, sehingga sebagian besar responden memiliki pandangan bahwa OVO memiliki citra yang baik di benak konsumen.

Tabel 8.

Deskripsi Penilaian Responden terhadap variabel Brand Image

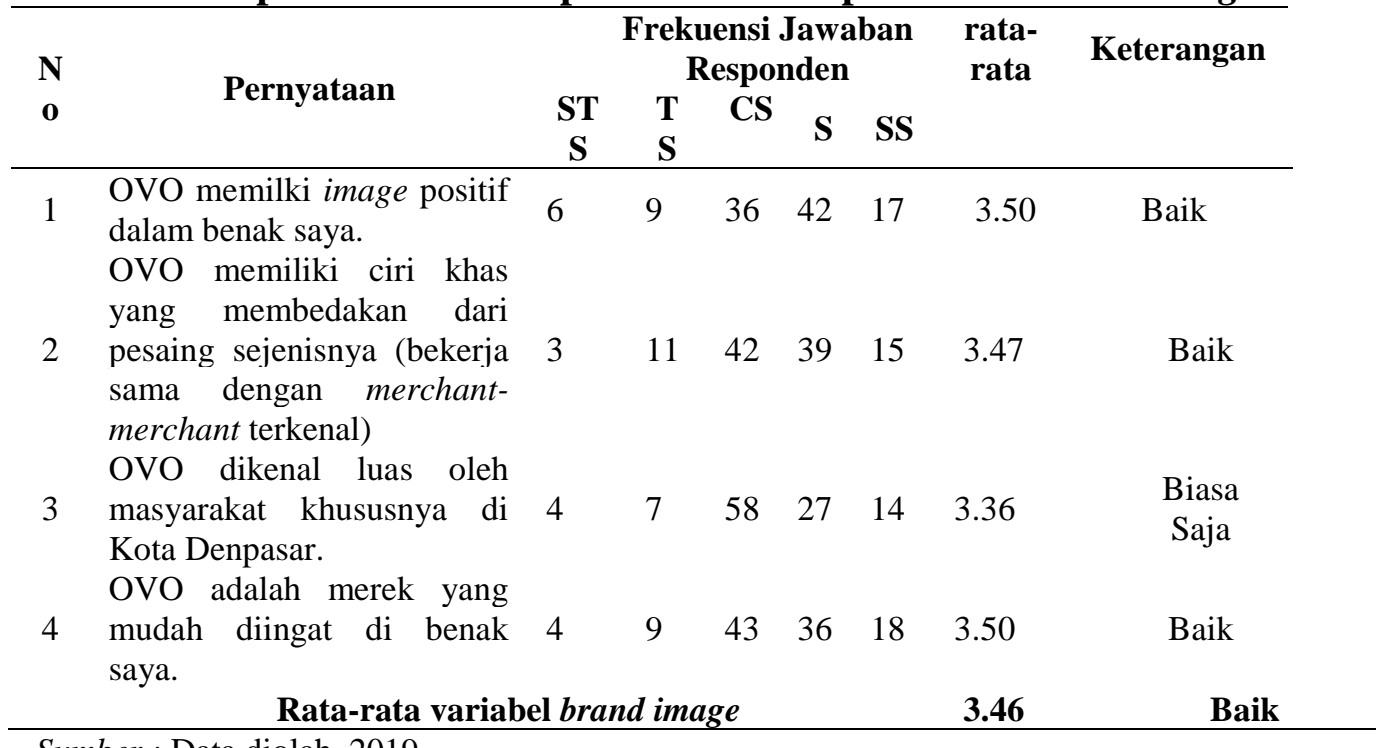

Sumber : Data diolah, 2019

Tabel 9.

Hasil Uji Normalitas Struktur 1

\begin{tabular}{cc}
\hline & Unstandardized Residual \\
\hline $\mathrm{N}$ & 110 \\
Kolmogorov-Smirnov & 0.641 \\
Asymp.Sig.(2-tailed) & 0.805 \\
\hline
\end{tabular}

Sumber : Data diolah, 2019

Berdasarkan hasil uji normalitas pada struktur 1, didapatkan hasil bahwa model persamaan regresi yang digunakan berdistribusi normal. Hasil ini berdasarkan nilai K-S yang didapatkan yaitu 0,641 serta Asym.Sig. yaitu 0,805. Nilai 0,805 lebih besar dari nilai alpha yang telah ditentukan yaitu 0,05.

Berdasarkan hasil uji normalitas pada struktur 2, didapatkan hasil bahwa model persamaan regresi yang digunakan berdistribusi normal. Hasil ini berdasarkan nilai K-S yang didapatkan yaitu 0,992 serta Asym.Sig. yaitu 0,279. Nilai 0,279 lebih besar dari nilai alpha yang telah ditentukan yaitu 0,05. 
Tabel 10.

Hasil Uji Normalitas Struktur 2

\begin{tabular}{cc}
\hline & Unstandardized Residual \\
\hline $\mathrm{N}$ & 110 \\
Kolmogorov-Smirnov & 0.992 \\
Asymp.Sig.(2-tailed) & 0.279 \\
\hline Sumber : Data diolah, 2019
\end{tabular}

Sumber : Data diolah, 2019

Untuk terbebas dari masalah multikolinearitas, nilai VIF yang harus dicapai adalah VIF yang bernilai lebih rendah dar 10. Nilai VIF ini berhasil dicapai oleh variabel E-WOM dan brand image sehingga menjadikan model regresi yang digunakan tidak memiliki masalah multikolinearitas. Untuk lebih jelasnya dapat dilihat pada Tabel 11 .

Tabel 11.

Hasil Uji Multikolinearitas

\begin{tabular}{cccc}
\hline Struktur & Variabel & Tolerance & VIF \\
\hline Struktur 1 & E-WOM $(\mathrm{X})$ & 1.000 & 1.000 \\
Struktur 2 & E-WOM $(\mathrm{X})$ & 0.493 & 2.028 \\
& Brand Image $(\mathrm{M})$ & 0.493 & 2.028 \\
\hline
\end{tabular}

Sumber : Data diolah, 2019

Tabel 12.

Hasil Uji Heteroskedastistas Struktur 1

\begin{tabular}{|c|c|c|c|c|c|}
\hline \multirow{2}{*}{ Model } & \multicolumn{2}{|c|}{ Unstandardized Coefficients } & \multirow{2}{*}{$\begin{array}{c}\text { Standardized } \\
\text { Coefficients } \\
\text { Beta }\end{array}$} & \multirow{2}{*}{$\mathbf{T}$} & \multirow{2}{*}{ Sig. } \\
\hline & B & Std. Error & & & \\
\hline $1 \quad$ (Constant) & 0.481 & 0.119 & & 4.045 & 0.000 \\
\hline E-WOM & -0.014 & 0.034 & -0.038 & -0.400 & 0.690 \\
\hline
\end{tabular}

Model yang digunakan pada penelitian haruslah bebas dari masalah heteorkedastisitas. Acuan agar terbebas dari heteroskedastisitas adalah dengan nilai signifikansi yang melebihi 0,05 . Syarat ini berhasil dicapai model penelitian yang digunakan pada penelitian ini dimana nilai signifikansi untuk variabel EWOM didapatkan yaitu 0,690 . Nilai ini menjadikan model yang digunakan tidak mengandung heteroskedastisitas

Tabel 13.

Hasil Uji Heteroskedastistas Struktur 2

\begin{tabular}{lccccc}
\hline Model & \multicolumn{2}{c}{$\begin{array}{c}\text { Unstandardized } \\
\text { Coefficients }\end{array}$} & $\begin{array}{c}\text { Standardized } \\
\text { Coefficients } \\
\text { Beta }\end{array}$ & T & Sig. \\
& B & $\begin{array}{c}\text { Std. } \\
\text { Error }\end{array}$ & Beta & & \\
\hline E-WOM & 0.768 & 0.143 & -0.145 & 5.386 & 0.000 \\
$\quad$ Brand Image & -0.050 & 0.046 & -0.143 & -1.095 & 0.276 \\
\hline Sumber $:$ Data diolah, 2019 & -0.061 & 0.057 & & -1.078 & 0.284 \\
\hline
\end{tabular}


Model penelitian yang digunakan haruslah terbebas dari masalah heteroskedastisitas. Untuk mencapai hal tersebut variabel independen harus di uji dan mendapatkan nilai signifikansi yang melebihi 0,05. Kedua variabel independen yang digunakan pada penelitian berhasil mendapatkan nilai signifikansi yang melebihi 0,05 . Hal ini memiliki arti bahwa model yang digunakan pada penelitian tidak terdapat heteroskedastisitas.

Berdasarkan hasil analisis jalur substruktur 1 seperti yang disajikan pada Tabel 14. maka persamaan strukturnya adalah sebagai berikut:

$$
\begin{aligned}
& M=\beta_{1} X+e_{1} \ldots . \\
& M=0,712 X+e_{1}
\end{aligned}
$$

Tabel 14.

Hasil Analisis Jalur Persamaan Regresi 1

\begin{tabular}{cccccc}
\hline Model & \multicolumn{2}{c}{ Unstandardized Coefficients } & $\begin{array}{c}\text { Standardized } \\
\text { Coefficients } \\
\text { Beta }\end{array}$ & T & Sig. \\
\hline $1 \quad$ (Constant) & 1.511 & 0.192 & - & 7.849 & 0.000 \\
E-WOM & 0.576 & 0.055 & 0.712 & 10.538 & 0.000 \\
$R$ Square: 0.507 & F Statistik : 111.041 & \multicolumn{2}{c}{ Sig F : 0.000} & & \\
\hline \multicolumn{2}{l}{ Sumber : Data diolah, 2019} & &
\end{tabular}

Tabel 15.

\begin{tabular}{|c|c|c|c|c|c|}
\hline \multirow{2}{*}{ Model } & \multicolumn{2}{|c|}{$\begin{array}{c}\text { Unstandardized } \\
\text { Coefficients }\end{array}$} & \multirow{2}{*}{$\begin{array}{c}\text { Standardized } \\
\text { Coefficients } \\
\text { Beta }\end{array}$} & \multirow{2}{*}{$\mathbf{T}$} & \multirow{2}{*}{ Sig. } \\
\hline & B & $\begin{array}{c}\text { Std. } \\
\text { Error }\end{array}$ & & & \\
\hline 1 (Constant) & 0.534 & 0.224 & & 2.382 & 0.019 \\
\hline E-WOM & 0.432 & 0.072 & 0.483 & 5.962 & 0.000 \\
\hline Brand image & 0.433 & 0.089 & 0.391 & 4.833 & 0.000 \\
\hline
\end{tabular}

Hasil Analisis Jalur Persamaan Regresi 2

R Square : $0,654 \quad$ F Statistik : $101.347 \quad$ Sig. F : 0.000

Sumber : Data diolah, 2019

Berdasarkan hasil analisis jalur substruktur 2 seperti yang disajikan pada Tabel 15. maka persamaan strukturalnya adalah sebagai berikut:

$$
\begin{aligned}
& Y=\beta_{2} X+\beta_{3} M+e_{2} \ldots \ldots \ldots \ldots \\
& Y=0,483 X+0,391 M+\varepsilon_{2}
\end{aligned}
$$

Berdasarkan perhitungan pengaruh error (Pei), didapatkan hasil pengaruh error $\left(\mathrm{Pe}_{1}\right)$ sebesar 0,702 dan pengaruh error $\left(\mathrm{Pe}_{2}\right)$ sebesar 0,588. Hasil koefisien determinasi total adalah 0,83 . Nilai determinasi total sebesar 0,83 mempunyai arti bahwa sebesar 83 persen variasi Purchase Intention dipengaruhi oleh variasi EWOM dan Brand Image, sedangkan sisanya sebesar 17 persen djelaskan oleh faktor lain yang tidak dimasukkan ke dalam model.

1) Menguji ketepatan model struktural

Berdasarkan hasil pengujian pada Tabel 14 dan Tabel 15 menghasilkan koefisien $\mathrm{F} \leq 0,05$ dengan koefisien signifikan $\leq 0,05$ hal tersebut menunjukkan 
E-WOM dan brand image berpengaruh secara simultan dan signifikan terhadap purchase intention.

Pengaruh E-WOM terhadap brand image. Hasil yang didapatkan dari analisis pengaruh E-WOM pada brand image adalah $\mathrm{H}_{1}$ diterima atau ditemukan adanya pengaruh yang positif antara hubungan E-WOM pada brand image. hasil ini didapat dari nilai sig. $\mathrm{t}$ yang dihasilkan dari analisis yaitu 0,000 . Nilai 0,000 memiliki nilai yang lebih kecil dari 0,05 . Hal ini menjadi dasar diterimanya $\mathrm{H}_{1}$ dan ditolaknya $\mathrm{H}_{0}$. Pengaruh yang ditemukan adalah pengaruh positif, hal ini dapat dilihat dari nilai koefisien beta yang bernilai positif yaitu 0,712 .

Pengaruh E-WOM terhadap purchase intention. Hasil yang didapatkan dari analisis pengarruh E-WOM pada purchase intentionadalah $\mathrm{H}_{2}$ diterima atau ditemukan adanya pengaruh yang positif antara hubungan E-WOM pada purchase intention. hasil ini didapat dari nilai sig. $t$ yang dihasilkan dari analisis yaitu 0,000. Nilai 0,000 memiliki nilai yang lebih kecil dari 0,05. Hal ini menjadi dasar diterimanya $\mathrm{H}_{1}$ dan ditolaknya $\mathrm{H}_{0}$. Pengaruh yang ditemukan adalah pengaruh positif, hal ini dapat dilihat dari nilai koefisien beta yang bernilai positif yaitu 0,483 .

Pengaruh brand image terhadap purchase intention. Hasil yang didapatkan dari analisis pengarruh brand image pada brand image adalah $\mathrm{H}_{3}$ diterima atau ditemukan adanya pengaruh yang positif antara hubungan brand image pada brand image. hasil ini didapat dari nilai sig. $\mathrm{t}$ yang dihasilkan dari analisis yaitu 0,000. Nilai 0,000 memiliki nilai yang lebih kecil dari 0,05. Hal ini menjadi dasar diterimanya $\mathrm{H}_{3}$ dan ditolaknya $\mathrm{H}_{0}$. Pengaruh yang ditemukan adalah pengaruh positif, hal ini dapat dilihat dari nilai koefisien beta yang bernilai positif yaitu 0,391 .

Tabel 16.

Pengaruh Langsung, Pengaruh Tidak Langsung dan Pengaruh Total EWOM (X), Brand Image (M), dan Purchase Intention(Y)

\begin{tabular}{cccc}
\hline Pengaruh Variabel & $\begin{array}{c}\text { Pengaruh } \\
\text { Langsung }\end{array}$ & $\begin{array}{c}\text { Pengaruh Tidak Langsung Melalui } \\
\text { Brand Equity } \\
(\mathbf{M})=(\boldsymbol{\beta} \mathbf{1} \text { x } \mathbf{\beta 3})\end{array}$ & $\begin{array}{c}\text { Pengaruh } \\
\text { Total }\end{array}$ \\
\hline E-WOM $\rightarrow$ Brand Image & 0.712 & - & 0.712 \\
$\begin{array}{c}\mathrm{E}-\mathrm{WOM} \rightarrow \text { Purchase } \\
\text { ntention }\end{array}$ & 0.483 & 0.278 & 0.761 \\
$\begin{array}{c}\text { Brand Image } \rightarrow \text { Purchase } \\
\text { Intention }\end{array}$ & 0.391 & - & 0.391 \\
\hline
\end{tabular}

Sumber : Data diolah, 2019

Interpretasi dari hasil uji sobeldapat dilihat pada Tabel 16. Hasil dari pengujian variabel mediasi yaitu persepsi nilai didapatkan $\mathrm{Z}$ hitung sebesar 4,1552 $>1,96$ dengan tingkat signifikan sebesar $0,000<0.05$ yang berarti $\mathrm{H}_{0}$ ditolak dan 
$\mathrm{H}_{1}$ diterima yang berarti variabel brand image memediasi variabel E-WOM terhadap purchase intention pada calon pengguna OVO di kota Denpasar.

Tabel 17.

Hasil Uji VAF

\begin{tabular}{ccccc}
\hline $\begin{array}{c}\text { Pengaruh } \\
\text { Variabel }\end{array}$ & $\begin{array}{c}\text { Pengaruh Tidak } \\
\text { Langsung }\end{array}$ & $\begin{array}{c}\text { Pengaruh } \\
\text { Total }\end{array}$ & VAF & $\begin{array}{c}\text { Jenis } \\
\text { Mediasi }\end{array}$ \\
\hline E-WOM $\rightarrow$ Purchase ntention & 0.278 & 0.761 & $36.5 \%$ & $\begin{array}{c}\text { partial } \\
\text { mediation }\end{array}$ \\
\hline
\end{tabular}

Sumber : Data diolah, 2019

Karena nilai VAF $(36,5 \%)$ lebih dari 20 persen, maka dapat dijelaskan bahwa ada efek mediasi yaitu partial mediation. Maka hipotesis yang menyatakan bahwa brand image berperan dalam memediasi E-WOM terhadap purchase intention diterima.

Hasil menunjukkan bahwa, semakin banyak informasi positif yang didapatkan konsumen mengenai OVO mobile payment, serta semakin banyak rekomendasi dan ajakan untuk mencoba OVO mobile payment maka citra merek atau brand image OVO akan semakin baik di benak konsumen.

Jalilvand \& Samiei (2012) penelitian-penelitian sebelumnya yang mengangkat topik mengenai hubungan E-WOM pada brand image mendapatkan hasil bahwa E-WOM memiliki pengaruh pada brand image. Penelitian yang dilakukan Torlak et al. (2014) menyebutkan bahwa hubungan WOM terhadap citra merek berpengaruh positif dan signifikan dalam penelitiannya mengenai merek ponsel untuk remaja. Penelitian oleh Pertiwi \& Sukawati (2017) menemukan bahwa WOM memiliki pengaruh positif dan signifikan terhadap citra merek. Penelitian Faresha \& Hendrawan (2017) menyatakan bahwa E-WOM berpengaruh secara positif dan signifikan terhadap citra merek situs travel online Traveloka di Kota Malang dan Prabandari et al. (2018) menyatakan bahwa WOM positif berpengaruh secara positif dan signifikan terhadap citra merek Teh Pucuk Harum di Kota Denpasar.

Hasil menunjukkan bahwa, semakin banyak informasi positif yang didapatkan konsumen mengenai OVO mobile payment, serta semakin banyak rekomendasi dan ajakan untuk mencoba OVO mobile payment maka tingkat niat beli pelanggan terhadap OVO mobile paymentakan semakin tinggi.

Penelitian oleh Akbar \& Rosita (2017) menemukan bahwa E-WOM memiliki pengaruh yang signifikan terhadap niat pembelian aplikasi music streaming JOOX. Hasil penelitian oleh Prabandari et al.(2018) menunjukkan bahwa WOM positif menunjukkan hasil yang positif dan signifikan terhadap niat beli Teh Pucuk Harum.Informasi yang terdapat pada E-WOM baik informasi dengan sinyal positif maupun informasi dengan sinyal negatif dapat mempengaruhi niat beli dari konsumen. Ketika suatu produk mendapat ulasan yang buruk, hal tersebut akan berdampak pada niat beli masyarakat kepada produk tersebut. Persepsi masyarakat mengenai produk dengan ulasan buruk tentu akan mempengaruhi pertimbangan konsumen ketika akan membeli suatu produk. Penelitian yang dilakukan oleh Sarah \& Rubiyanti (2016), Putri \& Prabowo 
(2015), Sa'ait et al. (2016) menemukan adanya hubungan positif antara E-WOM pada niat beli.

Hasil menunjukkan bahwa, semakin positif image OVO mobile payment, OVO memiliki ciri khas berbeda dari produk lain, OVO dikenal oleh kalangan luas serta mudah untuk mengingat merek OVO, maka niat beli terhadap OVO mobile payment akan semakin tinggi.Penelitian ini sesuai dengan penelitian oleh Wang \& Yang (2010) menemukan bahwa kredibilitas merek memiliki pengaruh terhadap niat beli konsumen pada industri otomotif di China. Penelitian oleh Rahmawan \& Pramono (2016) menemukan bahwa citra merek berpengaruh positif terhadap niat beli konsumen produk Handphone Xiaomi di Malang. Penelitian oleh Aberdeen (2016) menemukan bahwa citra merek secara langsung dan signifikan berpengaruh terhadap niat beli. Merek Coca - cola yang memiliki citra yang kuat mampu mempengaruhi niat beli konsumen secara positif dan signifikan. Penelitian oleh Akbar \& Rosita (2017) menemukan bahwa citra merek berpengaruh secara positif dan signifikan terhadap niat beli produk aplikasi music streaming JOOX. Hasil penelitian oleh Prabandari et al. (2018) menunjukkan bahwa brand image menunjukkan hasil yang positif dan signifikan terhadap niat beli Teh Pucuk Harum.

Pengaruh E-WOM terhadap purchase intention yang dimediasi oleh brand image pada calon pengguna OVO telah diuji dalam penelitian ini. Brand image memainkan peran penting untuk mempengaruhi persepsi pelanggan pada E-WOM dan purchase intention. Informasi, rekomendasi serta ajakan yang muncul melalui media sosial/onlineakan berpengaruh terhadap brand image suatu produk di benak konsumen sehingga konsumen memilih untuk membeli atau menggunakan OVO mobile payment atau memilih untuk tidak menggunakannya.

Hal ini sesuai dengan penelitian yang dilakukan oleh Agus \& Iswara (2017), dalam penelitian tersebut diketahui citra merek merupakan variabel pemediasi yang turut mempengaruhi dan menentukan efektifitas pengaruh E-WOM terhadap niat beli. Hasil penelitian oleh Prabandari et al. (2018) menunjukkan bahwa brand image menunjukkan hasil yang positif dan signifikan dalam memediasi WOM positif terhadap niat beli Teh Pucuk Harum.

Penelitian ini memperkuat penelitian-penelitian sebelumnya dalam memperjelas pengaruh variabel E-WOM terhadap purchase intention yang dimediasi oleh brand image. Hasil penelitian ini menunjukkan bahwa semakin banyak informasi - informasi positif yang disebarkan melalui media online maka semakin tinggi citra merek OVO di benak konsumen yang pada akhirnya akan meningkatkan niat untuk menggunakan OVO mobile payment.

Implikasi praktis penelitian ini menekankan pada manfaat untuk meningkatkan purchase intention dengan adanya dorongan melalui E-WOM dan brand image sehingga dapat meningkatkan niat untuk menggunakan produk OVO mobile payment. Lippo Group selaku pemilik produk OVO diharapkan untuk lebih meningkatkan kinerja dan kehandalan produknya lewat keluhankeluhan yang dilontarkan oleh para pengguna media sosial (online) sehingga meredam munculnya informasi negatif yang akan berdampak pada citra merek dibenak konsumen. 


\section{SIMPULAN}

Berdasarkan hasil pembahasan penelitian yang telah dilakukan, maka dapat disimpulkan E-WOM berpengaruh positif dan signifikan terhadap brand image pada OVO mobile payment. Dapat dikatakan bahwa, semakin banyak informasi positif ,mendapatkan rekomendasi dan ajakan untuk mencoba produk OVO maka citra merek atau brand imagedi benak konsumen akan semakin baik.

E-WOM berpengaruh positif dan signifikan terhadap purchase intention padaOVO mobile payment. Hasil menunjukkan bahwa, semakin banyak informasi positif, mendapatkan rekomendasi dan ajakan untuk mencoba produk OVO maka niat beli terhadap suatu produk akan semakin tinggi.

Brand image berpengaruh positif signifikan terhadap purchase intention pada OVO mobile payment. Hasil menunjukkan bahwa, semakin positif image produk, produk memiliki ciri khas berbeda dari produk lain, dikenal oleh kalangan luas serta mudah untuk mengingat merek tersebut, maka niat beli terhadap suatu produk akan semakin tinggi. Brand image memediasi pengaruh EWOM terhadap purchase intention pada OVO mobile payment. Ini berarti brand image memainkan peran penting untuk mempengaruhi persepsi pelanggan pada E-WOM dan purchase intention. Informasi, rekomendasi serta ajakan yang muncul melalui media sosial/onlineakan berpengaruh terhadap brand image suatu produk di benak konsumen sehingga konsumen memilih untuk membeli atau menggunakan OVO mobile payment atau memilih untuk tidak menggunakannya. Berdasarkan kesimpulan yang didapat saran-saran yang dapat diberikan adalah sebagai berikut:

Pihak perusahaan OVO sebaiknya lebih memperhatikan kinerja produk agar konsumen mendapatkan informasi yang cukup, memperoleh rekomendasi serta ajakan untuk menggunakan mobile payment merek OVO, sehingga mempengaruhi niat beli konsumen untuk menggunakan mobile payment merek OVO yang nantinya dapat menguntungkan perusahaan.

Pihak perusahaan OVO sebaiknya lebih bisa mengenalkan produknya ke masyarakat luas, meningkatkan image positif dimasyarakat serta semakin memiliki ciri khas tersendiri sehingga nantinya meningkatkan brand image di benak konsumen yang kemudian memberikan rekomendasi terhadap calon konsumen lainnya.

Bagi peneliti selanjutnya diharapkan dapat memperluas cakupan wilayah penelitian misalnya dengan mengambil lokasi di seluruh Bali atau wilayah selain Kota Denpasar atau Indonesia.

\section{REFERENSI}

Aberdeen. (2016). How To Solve Chemistry Problem.

Adriyati, R., \& Indriani, F. (2017). Pengaruh Electronic Word Of Mouth Terhadap Citra Merek Dan Minat Beli Pada Produk Kosmetik Wardah. Diponogoro Journal Of Management,6(4), 1-14.

Agus, I. G., \& Iswara, D. (2017). Peran Brand Image Dalam Memediasi Pengaruh Electronic Word Of Mouth Terhadap Purchase ( Studi Kasus Pada Produk 
Smartphone Samsung di Kota Denpasar ) Fakultas Ekonomi dan Bisnis Universitas Udayana ( Unud ), Bali , Indonesia Perkembangan tekonologi yang s, 6(8), 3991-4018.

Akbar, I., \& Rosita., N. H. (2017). Pengaruh Electronic Word of Mouth dan Brand Image Terhadap Minat Pembelian Music Streaming JOOX. Jurnal Ilmiah Mahasiswa Fakultas Ekonomi Dan Bisnis Brawijaya, 2(5), 1-17.

Al-Zu'bi, H. A. (2011). Organizational Citizenship Behavior and Impacts Knowledge Sharing: An Empirical Study. International Business Research, 4(3), 221-227.

Anggitasari, A. M. (2016). Pengaruh Ewom Terhadap Brand Image Dan Brand Trust, Serta Dampaknya Pada Minat Beli Produk Smartphone Iphone (Studi Pada Masyarakat Di Yogyakarta). Jurnal Manajemen Bisnis Indonesia,5(3), 266-275.

Annafik, A. F., \& Rahardjo, M. (2012). Analisis Pengaruh Kualitas Produk, Harga, Daya Tarik Iklan terhadap Minat Beli Sepeda Motor Yamaha,. Diponegoro Journal Of Management, 1(2), 274-281.

Berger, L. P., \& Luckmann, T. (1966). The Social Construction of Reality. US: Anchor Book.

Calvin, \& Samuel, H. (2014). Analisis Pengaruh Iklan, Kepercayaan Merek, dan Citra Merek Terhadap Minat Beli Konsumen. Jurnal Manajemen Pemasaran Petra, 2(1).

Cong, Y., \& Zheng, Y. (2017). A Literature Review of the Influence of Electronic Word-of-Mouth on Consumer Purchase Intention. Open Journal of Business and Management, 5(1), 543-549.

Elseidi, R. I., \& El-Baz, D. (2016). Electronic Word Of Mouth Effects On Consumers Brand Attitudes, Brand Image And Purchase Intention: An Empirical Study In Egypt. The Bussines and Management Review, 7(5), 268-276.

Faharani, M., Taghadosi, M., \& Behboudi, M. (2011). An Exploration of the Relationship between Transformational Leadership and Organizational Commitment: The Moderating Effect of Emotional Intelligence: Case Study in Iran. International Business Research., 4(4), 211-217.

Faresha, K. S., \& Hendrawan, D. (2017). Pengaruh Electronic Word of Mouth Terhadap Purchase Intention yang Dimediasi oleh Variabel Brand Image Pada Situs Travel Online Traveloka (Studi Pada Pengguna di Kota Malang). Jurnal Ilmiah Mahasiswa Fakultas Ekonomi Dan Bisnis Brawijaya, 2(7), 1- 
10.

Febriana, L., \& Rumyeni. (2016). The Influence of Word Of Mouth Communication towards Brand Image of Iphone on Student of Political Science and Social Science Faculty University of Riau. Jurnal Online Mahasiswa Fakultas Ilmu Sosial Dan Ilmu Politik., 3(2), 1-15.

Ferdinand, A. (2002). Structural Equation Modelling dalam Penelitian Manajemen, Aplikasi Model-model Rumit dalam Penelitian untuk Tesis Magister dan Disertasi Doktor. Semarang: Universitas Diponegoro.

Hsu, C. L., Chuan-Chuan Lin, J., \& Chiang, H. S. (2013). The Effects of Blogger Recommendations on Customers online shopping intentions. Internet Research, 23(1), 69-88.

Kamilah, G., \& Aniek, W. (2017). Pengaruh Labelisasi Halal Dan Brand Image Terhadap Keputusan Pembelian Melalui Minat Beli. Jurnal Ilmu Dan RisetManajemen, 6(2), 1-18.

Kotler, A. (2012). Prinsip-Prinsip Pemasaran.

Lien, C., Wen, H., Huang, L., \& Wu, K. (2015). Online Hotel Booking: The Effects Of Brand Image, Price, Trust And Value On Purchase Intentions. Asia Pacific Management Review, 20(4), 210-218.

Maghfiroh, A., Arifin, Z., \& Sunarti. (2016). Pengaruh Citra Merek Terhadap Minat Beli Dan Keputusan Pembelian (Survei pada Mahasiswa Program Studi Administrasi Binis Tahun Angkatan 2013 / 2014 Fakultas Ilmu Administrasi Universitas Brawijaya Malang Pembeli Indosat). Jurnal Administrasi Bisnis, 40(1), 132-140.

Martinez, B., \& Soyoung, K. (2012). "Predicting purchase intention for private sale sites." Emeraldinsight., 2(4), 1361-2026.

Mowen, C., \& Minor., J. M. (2002). Perilaku Konsumen. Jakarta: Erlangga.

Pertiwi, K. Y., \& Sukawati., T. G. R. (2017). Brand Image Memediasi WOM terhadap Niat Menggunakan Wedding Service di Cahaya Dewi Beauty Salon Denpasar. E-Jurnal Manajemen Universitas Udayana,6(5), 26422670.

Prabandari, A. A. M., Putri, I. P. G. S., \& Yasa, N. N. K. (2018). The Role Of Brand Image In Mediating The Influence Of Positive Word Of Mouth OnConsumer's Purchase Intention. Jurnal Ilmiah Fakultas Ekonomi Dan Bisnis Unud., 6(2), 86-103. 
Pradipta, H. O., \& Mashariono. (2015). Pengaruh Citra Merek, Periklanan Terhadap Minat Beli Konsumen Thermometer Onemed Di Surabaya. Jurnal Ilmu Dan Riset Manajemen,4(7), 1-19.

Putri, L. E. D., \& Prabowo, F. S. A. (2015). Pengaruh Electronic Word Of Mouth (E-Wom) Terhadap Purchase Intention (Studi Kasus Pada Go-Jek Indonesia). E-Proceeding of Management, 2(3), 2865-2871.

Rahmawan, R. R., \& Pramono, S. (2016). Pengaruh Electronic Word of Mouth Terhadap Niat Pembelian yang Dimediasi oleh Citra Merek Pada Produk Handphone Xiaomi di Malang. Jurnal Ilmiah Fakultas Ekonomi Dan Bisnis Brawijaya, 2(4), 1-18.

Randi, \& Heryanto, M. (2016). Pengaruh Citra Merek Terhadap Minat Beli Pada Makanan Fast Food Ayam Goreng (Studi Pada Konsumen Texas Chicken Pekanbaru). Jurnal Online Mahasiswa Fakultas Ilmu Sosial Dan IlmuPolitik, 3(2), 1-9.

Reza Jalilvand, M., \& Samiei, N. (2012). The effect of electronic word of mouth on brand image and purchase intention. Marketing Intelligence \& Planning, 30(4), 460-476. https://doi.org/10.1108/02634501211231946

Sa'ait, N., Kenyan, A., \& Nazrin, M. F. (2016). The Effect of E-WOM on Customer Purchase Intention. International Academic Research Journal of Social Science, 2(1), 73-80.

Saleem, F., Rafique, B., Mehmood, Q., Irfan, M., Saleem, R., Tariq, S., \& Akram, G. (2013). The determination of capital structure of oil and gas firms listed on Karachi stock exchange in Pakistan. Interdisciplinary Journal of Contemporary Research in Business, 4(9).

Samuel, H., \& Lianto, A. S. (2014). Pengaruh Analisis eWOM, Brand Image, Brand Trust dan Minat Beli Produk Smartphone di Surabaya. Jurnal Universitas Kristen Petra Surabaya., 8(2).

Sarah, T. M. S., \& Rubiyanti, R. N. (2016). Pengaruh Electronic Word Of Mouth Terhadap Minat Beli Pada Café Du71a Bandung. E-Proceeding of Management, 3(2), 2087-2093.

Suwarduki, P. R., Yulianto, E., \& Mawardi., M. K. (2016). Pengaruh Electronic Word of Mouth terhadap Citra Destinasi serta Dampaknya pada Minat dan Keputusan Berkunjung (Survei pada Follower Aktif Instagram Ind travel yang telah mengunjungi destinasi wisata di Indonesia). Jurnal Administrasi Bisnis., 37(2), 1-10.

Torlak, O., Ozkara, B. Y., Tiltay, M. A., Cengiz, H., \& Dulger, M. F. (2014). The 
Effect of Electronic Word of Mouth on Brand Image and Purchase Intention: An Application Concerning Cell Phone Brands for Youth Consumers in Turkey Eskisehir Osmangazi University University of Nevada. Journal of Marketing Development and Competitiveness, 8(2), 6168. https://doi.org/10.1108/02634501211231946

Wang, Y. ., \& Tsai, C. F. (2014). The Relationship between Brand Image and Purchase Intention: Evidence from Award Winning Mutual Funds. The International. Journal of Business and Finance Research., 8(2), 27-40.

Wang, \& Yang. (2010). "The effect of brand credibility on consumers' brand purchase intention in emerging economies: the moderating role of brand awareness and brand image",. Journal of Global Marketing, 23(3). 